\title{
Influence of the Substitution Pattern Effect in Achiral and Rigid Spacers over the Folding of Helical Poly(phenylacetylene)s ${ }^{\dagger}$
}

\author{
Zulema Fernández, Elena Rivadulla-Cendal, Emilio Quiñoá and Félix Freire * \\ Centro Singular de Investigación en Química Biolóxica e Materiais Moleculares (CiQUS), Universidade de \\ Santiago de Compostela, 15705 Santiago de Compostela, Spain; zulema.fernandez@uc.es (Z.F.); \\ * Correspondence: felix.freire@usc.es \\ + Presented at the 24th International Electronic Conference on Synthetic Organic Chemistry, 15 November- \\ 15 December 2020; Available online: https://ecsoc-24.sciforum.net/.
}

Received: date;

\begin{abstract}
The design, synthesis and structure elucidation of helical polymers with a predominant helical sense have been actively studied during the last years due to the different applications that these materials can present. The helical sense of a polymer can be determined by the chirality of the pendants and is directly related to the distance from the chiral centre to the backbone. In order to achieve the best folding, the distance between the polymeric backbone and the chiral centre should be small, so the closer is the pendant to the backbone the better is the helical control. Nevertheless, few examples have demonstrated that the helical control is also possible when a spacer is placed between the pendant and the backbone. Related to this, our research group has proven that it is possible to have chiral teleinduction when the chiral centre is separated from the backbone through a flexible spacer. Recently, we have also demonstrated that the transmission of information is also possible when a long rigid and achiral spacer is employed observing that, although the chiral centre is placed in a remote position, its chirality is transmitted to the polyene backbone through a previous organization in a helical fashion of the rigid spacer. Herein we describe another family of polymers bearing an achiral rigid spacer between the pendant and the backbone, evaluating the effect that the aromatic substitution pattern of the rigid spacer has in the final folding of the polymer.
\end{abstract}

Keywords: keyword 1; keyword 2; keyword 3 (List three to ten pertinent keywords specific to the article; yet reasonably common within the subject discipline.)

\section{Introduction}

In the last years, dynamic helical polymers have emerged as an attractive field due to the possibility of tuning the helical sense and/or the elongation of the helical structure. These modifications in the helical scaffold are triggered by the addition of external stimuli that produce modifications in the pendant groups [1]. In the case of chiral dynamic helical polymers, a conformational change is produced in the chiral moiety, whereas in the case of achiral polymers the modulation of the pendant is produced by the addition of a chiral molecule. In both cases the changes produced in the helical structures are related to the spatial dispositions adopted by the substituents or the associated species at the pendant groups. In these materials the mechanism of helical induction depends on the distance between the pendant and the backbone and it should be short to have an effective communication. Nevertheless, some examples have demonstrated that the transmission of chiral information from a remote position can also occur at long distances through space, overcoming the distance generated by the spacer-teleinduction [2]-or by the achiral spacer itselfconformational switch [3]-We have recently reported for the first time a novel mechanism for the transmission of chiral information in helical polymers derived from poly(phenylacetylene)s (PPAs) 
bearing an oligo( $p$-phenyleneethynylene) (OPE) spacer between the pendant and the backbone [4]. In this new family of polymers-poly( $p$-oligophenyleneethynylene)s (POPEPAs) - the helical induction is produced by a combination of chiral teleinduction together with a chiral harvesting process - the chiral information is transmitted to the achiral spacer resulting into a stacking of the OPE units, which is further harvested by the polyene backbone - and is effective for a distance of $2.4 \mathrm{~nm}$. Moreover this helix induction was observed to occur despite modifying the aromatic substitution pattern.

Taking into account these remarkable results, we decided to evaluate the effect that the introduction of a meta- substituted OPE spacer [oligo( $m$-phenyleneethynylene)] will have over the folding of the helical structure.

\section{Materials and Methods}

To carry out these studies different oligo( $m$-phenyleneethynylene)phenylacetylene monomers were prepared containing the ortho-, meta- and para- $-o-, m$ - and $p$-(2)-ethynylanilide of $(R)-\alpha-$ methoxy- $\alpha$-phenylacetic acid (MPA) and further polymerized by using a $\mathrm{Rh}(\mathrm{I})$ catalyst.

General procedure for monomer synthesis: 3-(iodophenylethynyl)trimethylsilane (1.0 equiv), bis(triphenylphosphine)palladium(II) dichloride ( $\mathrm{PdPPh}_{3} \mathrm{Cl}_{2}, 0.004$ equiv) and tiphenylphosphine $\left(\mathrm{PPh}_{3}, 0.016\right.$ equiv) were introduced in a round-bottom flask and disolved in $\mathrm{Et}_{3} \mathrm{~N}$ (10 mL, 1.0 equiv). Next 2-, 3- or 4-ethynylaniline was added and the reaction was stirred overnight at rt. The crude was purified by flash cromatography (70-230 mesh) employing hexane/ethyl acetate $(70 / 30 \%(v / v))$ as eluent. The obtained compound was disolved in a THF:MeOH (50/50\% $(v / v)$ ) and $\mathrm{K}_{2} \mathrm{CO}_{3}$ (3.0 equiv) was added. Once the reaction was finished, the crude was washed with Mili-Q water $(3 \times 15 \mathrm{~mL})$ and dried over $\mathrm{Na}_{2} \mathrm{SO}_{4}$. Finally, to obtain the desired monomers, $(R)-\alpha$-methoxy- $\alpha$-phenylacetic acid (MPA, 1.2 equiv), 1-[bis(dimethylamino)methylene]-1 $H$-1,2,3-triazolo[4,5- $b$ ]pyridinium 3-oxid hexafluorophosphate (HATU, 1.2 equiv) and $3 H$-[1,2,3]-triazolo[4,5-b]pyridin-3-ol (HOAT, 1.2 equiv) were introduced in a round bottom flask and solubilized in DCM $(0.1 \mathrm{M})$. Next diisopropilamine (DIPEA, 1.2 equiv) was added and, after $15 \mathrm{~min}$, the correspondent aniline (1.0 equiv) was added. The reaction was stirred overnight at $\mathrm{rt}$ and the crude was purified by flash chromatography (70-230 mesh) employing hexane/ethyl acetate $(70 / 30 \%(v / v))$ as eluent.

- $\quad(R)-N-(2-((3-e t h y n y l p h e n y l) e t h y n y l) p h e n y l)-2-m e t h o x y-2-p h e n y l a c e t a m i d e \quad[o-(R)-2] \quad(78 \%$ yield). ${ }^{1} \mathbf{H}$ NMR $\left(300 \mathrm{MHz}, \mathrm{CDCl}_{3}\right) \delta_{\mathrm{H}}(\mathrm{ppm}): 9.63(\mathrm{~s}, 1 \mathrm{H}), 8.47(\mathrm{~d}, 1 \mathrm{H}), 7.81(\mathrm{~s}, 1 \mathrm{H}), 7.38(\mathrm{~m}, 13 \mathrm{H})$, $7.09(\mathrm{t}, 1 \mathrm{H}), 4.83(\mathrm{~s}, 1 \mathrm{H}), 3.50(\mathrm{~s}, 3 \mathrm{H}), 3.14(\mathrm{~s}, 1 \mathrm{H}) .{ }^{13} \mathrm{C}$ NMR $\left(75 \mathrm{MHz}, \mathrm{CDCl}_{3}\right) \delta_{\mathrm{c}}(\mathrm{ppm}): 166.6$, 136.3, 134.1, 132.5, 129.7, 128.9, 128.8, 127.4, 126.2, 124.5, 121.0, 120.1, 116.5, 109.3, 92.6, 82.0, 81.1, 79.3, 53.8. MS (ESI) $\mathrm{m} / \mathrm{z}$ calculated for $\mathrm{C}_{25} \mathrm{H}_{20} \mathrm{NO}_{2}$, [M + H] : 366.1416, found: 366.1417 .

- $\quad(R)-N-(3-((3-e t h y n y l p h e n y l) e t h y n y l) p h e n y l)-2-m e t h o x y-2-p h e n y l a c e t a m i d e \quad[m-(R)-2] \quad(77 \%$ yield). ${ }^{1} \mathrm{H}$ NMR $\left(300 \mathrm{MHz} \mathrm{CDCl}_{3}\right) \delta_{\mathrm{H}}(\mathrm{ppm}): 8.65(\mathrm{~s}, 1 \mathrm{H}), 7.84(\mathrm{~s}, 1 \mathrm{H}), 7.60(\mathrm{~d}, 2 \mathrm{H}), 7.37(\mathrm{~m}, 10 \mathrm{H})$, $4.75(\mathrm{~s}, 1 \mathrm{H}), 3.43(\mathrm{~s}, 3 \mathrm{H}), 3.13(\mathrm{~s}, 1 \mathrm{H}) .{ }^{13} \mathrm{C}$ NMR $\left(75 \mathrm{MHz}, \mathrm{CDCl}_{3}\right) \delta_{\mathrm{c}}(\mathrm{ppm}): 169.7,138.3,137.3$, 135.9, 132.7, 129.9, 129.5, 129.2, 128.4, 127.9, 124.4, 123.5, 123.3, 120.7, 90.3, 89.2, 84.3, 83.3, 57.7. MS (ESI) $m / z$ calculated for $\mathrm{C}_{25} \mathrm{H}_{20} \mathrm{NO}_{2}$, [M + H]: 366.1416, found: 366.1486 .

- $\quad(R)-N-(4-((3-e t h y n y l p h e n y l) e t h y n y l) p h e n y l)-2-m e t h o x y-2-p h e n y l a c e t a m i d e \quad[p-(R)-2] \quad(69 \%$ yield). ${ }^{1} \mathbf{H}$ NMR $\left(300 \mathrm{MHz}, \mathrm{CDCl}_{3}\right) \boldsymbol{\delta}_{\mathrm{H}}(\mathrm{ppm}): 8.63(\mathrm{~s}, 1 \mathrm{H}), 7.62(\mathrm{t}, 3 \mathrm{H}), 7.41(\mathrm{~m}, 10 \mathrm{H}), 4.75(\mathrm{~s}, 1 \mathrm{H})$, $3.45(\mathrm{~s}, 3 \mathrm{H}), 3.10(\mathrm{~s}, 1 \mathrm{H}) .{ }^{13} \mathrm{C}$ NMR $\left(75 \mathrm{MHz}, \mathrm{CDCl}_{3}\right) \delta_{\mathrm{c}}(\mathrm{ppm}): 169.6,138.3,137.2,135.8,133.2$, 132.5, 129.5, 129.2, 127.8, 124.4, 123.2, 120.1, 119.4, 90.4, 88.6, 84.3, 83.3, 57.7. MS (ESI) $\mathrm{m} / \mathrm{z}$ calculated for $\mathrm{C}_{25} \mathrm{H}_{20} \mathrm{NO}_{2}$, [M + H]: 366.1416, found: 366.1488 .

Once the monomers were obtained, the polymers were synthesized. The corresponding monomer (1.0 equiv) was introduced as a solid in a flask - sealed ampoule-, previously dried under vacuum and flushed with Ar for three times and dissolved in dry THF. Next a solution of rhodium norbornadiene chloride dimer $\left([\mathrm{Rh}(\mathrm{nbd}) \mathrm{Cl}]_{2}, 0.005\right.$ equiv, THF) and $\mathrm{Et}_{3} \mathrm{~N}$ (0.05 equiv) were added and the mixture was stirred overnight at $20^{\circ} \mathrm{C}$. The resulting polymers were diluted in $\mathrm{CH}_{2} \mathrm{Cl}_{2}$ and precipitated in a large amount of $\mathrm{MeOH}$, centrifuged and reprecipitated in hexane and centrifuged again. The polymers were obtained in high yield (Table 1) and showed Raman spectra characteristic of cis-polyene backbones. 
Table 1. Yield and Mn obtained for the synthesized polymers.

\begin{tabular}{ccc}
\hline Polymer & Yield & Mn $^{1}$ \\
\hline o-poly-2 & $73 \%$ & 16.150 \\
$m$-poly-2 & $90 \%$ & 16.070 \\
p-poly-2 & $82 \%$ & 16.104 \\
\hline
\end{tabular}

${ }^{1}$ GPC studies were carried out in a Waters Alliance equipped with Phenomenex GPC columns $\left(10^{3}\right.$ $\AA$, $10^{4} \AA$ and $10^{5} \AA$ ). The amount of polymer used was $0.3 \mathrm{mg} \mathrm{mL}^{-1}$. THF was used as eluent (flow rate: $1 \mathrm{~mL} \cdot \mathrm{min}^{-1}$ ) and as inner standard, polystyrene narrow standards (PSS) were used.

poly-1 series were synthesized according to the previously reported procedure [5].

CD measurements were done in a Jasco-720 and UV spectra were registered in a Jasco V-630. The amount of polymer used for the measurements was $0.2 \mathrm{mg} \mathrm{mL}^{-1}$. Measurements were performed in a $1 \mathrm{~mm}$ quartz cell.

\section{Results and Discussion}

Once the polymers were obtained (Figure 1), structural and dynamic behavior studies were performed and the obtained results were compared to their corresponding PPAs counterparts (poly-1 series) [5].

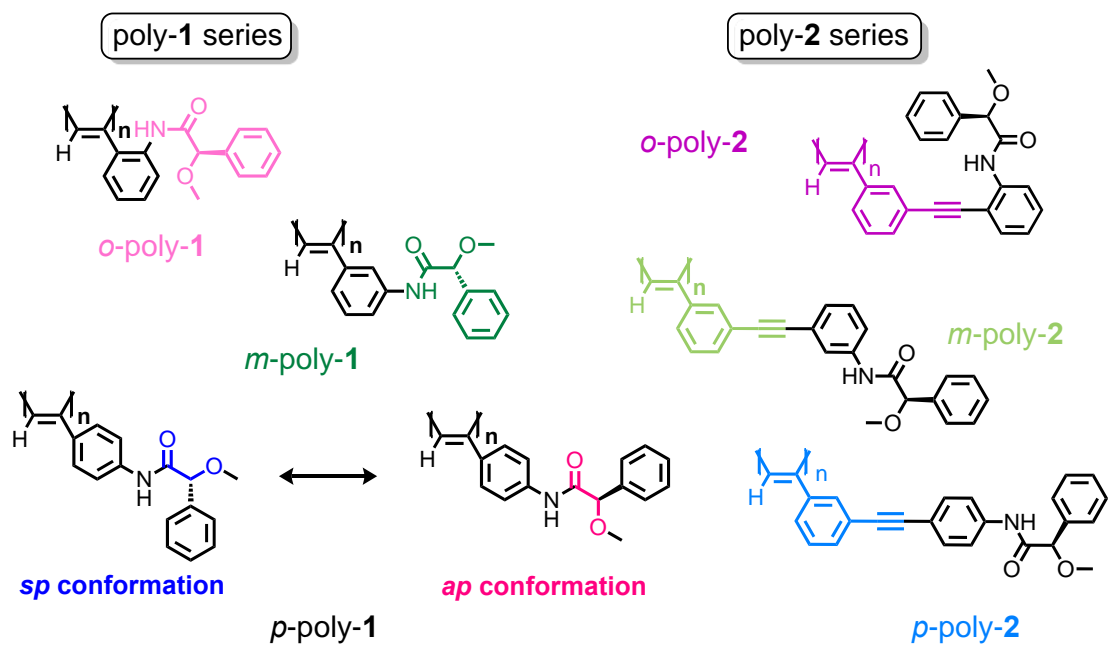

Figure 1. Structures of the synthesized polymers.

\section{1. o-Poly-2}

As mentioned above, o-poly-2 presents an elongated cis-transoidal polyene backbone, adscribed to the steric hindrance caused by the proximity between the pendant and the backbone. This stretching was also observed for the corresponding ortho- substituted PPA (o-poly-1). However, comparision of the spectrocopic data obtained for these two helical polymers-o-poly-1 and o-poly2 -reveals a compression in the case of o-poly-2. This indicates that the congestion observed for opoly-1 is released by the introduction of the spacer-UV bathocromic shift from $508 \mathrm{~nm}$ to $430 \mathrm{~nm}-$ resulting into a better accomodation of the pendant group (Figure 2a).

\section{2. $m$-Poly-2}

In the case of $m$-poly-2, the introduction of the rigid spacer results into a polymer without helical preference (null CD signal in the vinylic region). This lack of helical sense is due to the six different conformations that the pendant may adopt during the polymerization process. Therefore, several conformations of similar energy will coexist within the same polymer, resulting in an ineffective transmission of chiral information (Figure $2 b$ ). 
Previous studies have revealed that $p$-poly-1 presents a poor CD signal (null CD signal in the vinylic region). This result arises from the conformation equilibrium between the ap (antiperiplanar, $\mathrm{O}=\mathrm{C}-\mathrm{C}-\mathrm{OMe}$ dihedral angle $180^{\circ}$ ) and $s p$ (synperiplanar, $\mathrm{O}=\mathrm{C}-\mathrm{C}-\mathrm{OMe}$ dihedral angle $0^{\circ}$ ) conformations that the pendant presents, resulting in an axially racemic polymer [6]. This coexistence equilibrium is shifted when the rigid spacer is introduced, resulting in a polymer with a defined helical sense. Moreover comparison of the UV-Vis spectra shows a helical stretching for $p$-poly-2, produced by the proximity between the pendant and the backbone despite the length of the spacer. This stretching was confirmed by DSC measurements that revealed the adoption of a cis-transoidal scaffold (Figure 2c).

a)
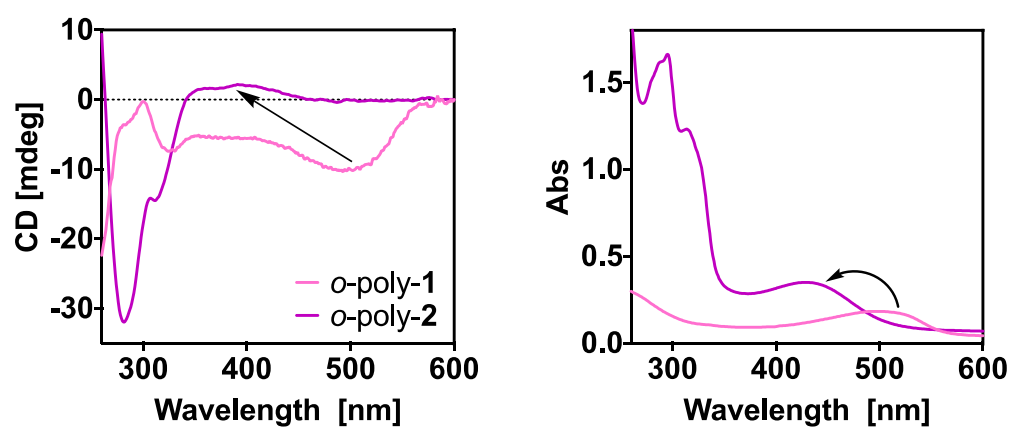

b)
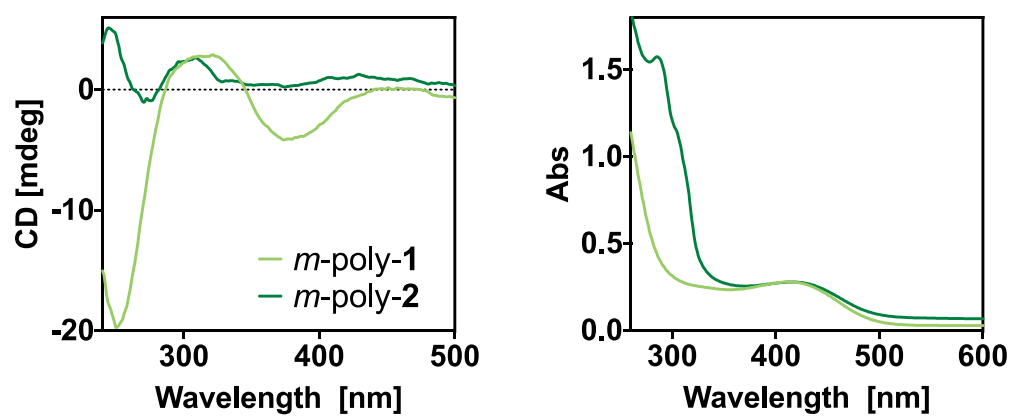

c)
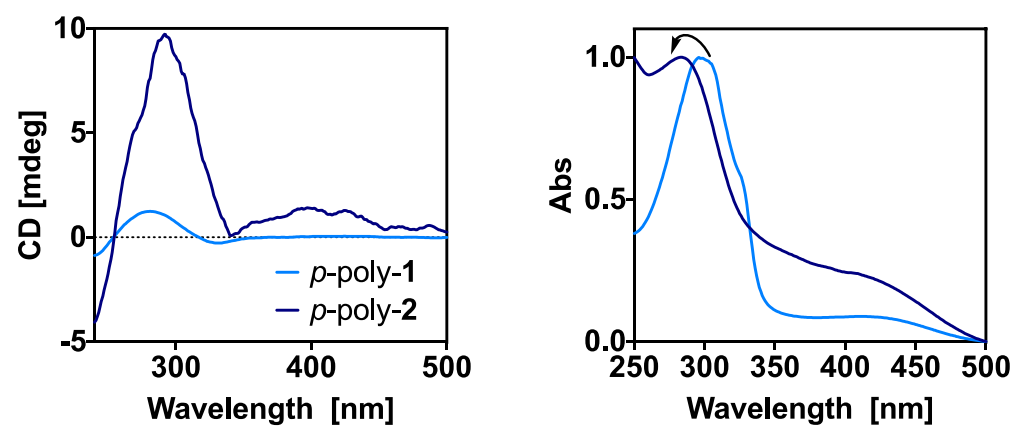

Figure 2. CD and UV-Vis spectra comparisons for (a) $o$-poly-1 and $o$-poly-2, (b) $m$-poly-1 and $m$-poly2 and (c) $p$-poly-1 and $p$-poly-2.

\section{Conclusions}

In conclusion, a novel family of polymers bearing highly conjugated OPE pendants - [oligo $(m-$ phenyleneethynylene)] - was described. Despite increasing the distance between the pendant and the backbone, an effective transmission of chiral information ocurred in the case of $o$ - and $p$-poly-2. These results open new horizons in the development of novel helical structures with applications in different fields.

Acknowledgments: Financial support from MINECO (PID2019-109733GB-I00), Xunta de Galicia (ED431C 2018/30, Centro Singular de Investigación de Galicia acreditación 2019-2022, ED431G 2019/03 and Z. F. thanks 
for her predoctoral fellowship) and the European Regional Development Fund (ERDF) is gratefully acknowledged.

Conflicts of Interest: The authors declare no conflict of interest.

\section{References}

1. Leiras, S.; Freire, F.; Seco, J.M.; Quiñoá, E.; Riguera, R. Controlled modulation of the helical sense and the elongation of poly(phenylacetylene)s by polar and donor effects. Chem. Sci. 2013, 4, 2735-2743.

2. (a) Rodríguez, R.; Quiñoá, E.; Riguera, R.; Freire, F. Multistate Chiroptical Switch Triggered by StimuliResponsive Chiral Teleinduction. Chem. Mater. 2018, 30, 2493-2497. (b) Rodríguez, R.; Quiñoá, E.; Riguera, R.; Freire, F. Stimuli-Directed Colorimetric Interconversion of Helical Polymers Accompanied by a Tunable Self-Assembly Process. Small 2019, 15, 1805413.

3. (a) Ousaka, N.; Inai, Y. Transfer of Noncovalent Chiral Information along an Optically Inactive Helical Peptide Chain: Allosteric Control of Asymmetry of the C-Terminal Site by External Molecule that Binds to the N-Terminal Site. J. Org. Chem. 2009, 74, 1429-1439. (b) Fukuda, M.; Rodríguez, R.; Fernández, Z.; Nishimura, T.; Hirose, D.; Watanabe, G.; Quiñoá, E.; Freire, F.; Maeda, K. Macromolecular helicity control of poly(phenyl isocyanate)s with a single stimuli-responsive chiral switch. Chem. Commun. 2019, 55, 79067909.

4. Fernández, Z.; Fernández, B.; Quiñoá, E.; Riguera, R.; Freire, F. Chiral information harvesting in helical poly(acetylene) derivatives using oligo(p-phenyleneethynylene)s as spacers. Chem. Sci. 2020, 11, 7182-7187.

5. Rodríguez, R.; Quiñoá, E.; Riguera, R.; Freire, F. Architecture of Chiral Poly(phenylacetylene)s: From Compressed/Highly Dynamic to Stretched/Quasi-Static Helices. J. Am. Chem. Soc. 2016, 138, 9620-9628.

6. Freire, F.; Seco, J.M.; Quiñoá, E.; Riguera, R. Chiral Amplification and Helical-Sense Tuning by Mono- and Divalent Metals on Dynamic Helical Polymers. Angew. Chem. Int. Ed. 2011, 50, 11692-11696.

Publisher's Note: MDPI stays neutral with regard to jurisdictional claims in published maps and institutional affiliations.

(C) 2020 by the authors. Submitted for possible open access publication under the terms and conditions of the Creative Commons Attribution (CC BY) license (http://creativecommons.org/licenses/by/4.0/). 